\title{
Generalized livedo reticularis like eruption induced by trimethoprim/sulfamethoxazole: A case report with concomitant myelosuppression
}

\author{
Pinar Incel Uysal', Basak Yalcin', Onder Bozdogan² \\ ${ }^{1}$ Dermatology Department, Ankara Numune Training and Research Hospital, Ankara, Turkey, ${ }^{2}$ Pathology Department, \\ Ankara Numune Training and Research Hospital, Ankara, Turkey
}

Corresponding author: Dr. Pinar Incel Uysal, E-mail: pinarincel@hotmail.com

\begin{abstract}
Livedo reticularis is a reticular discoloration of the skin because of the vascular anatomy of the skin. The condition most commonly affects the legs. Drug induced livedo reticularis which is an acknowledged side effect of amantadine, tends to be widespread, asymptomatic, benign rash. There are also reports of livedoid eruption induced with drugs including dapsone, imatinibe, gefitinibe. We describe a case of livedo reticularis like eruption and haemotological toxicity with trimetophrim-sulfamethoxazole. The purpose of this report is to remind clinicians of this rare, benign side effect of the common prescribed medication.
\end{abstract}

Key words: Livedoid eruption; Skin rash; Trimetophrim-Sulfamethoxazole

\section{INTRODUCTION}

Livedo reticularis is a network like livedoid eruption which commonly occurs after physical exposure such as cold. Drug induced livedo reticularis is a very rare manifestation. In the literature there are reports that were associated with drugs including amantadine, dapsone, imatinibe, rasagiline [1-5]. These reactions usually show benign course and resolve without complication after discontinuation of the causative drug.

TMP-SMX is commonly used antimicrobial drug which has a wide range of adverse effects. Severe liver failure, skin rash, early onset bone morrow changes are included in idiosyncratic reactions. Skin rash is a common adverse effect. Although the majority of these are mild and self-limited reactions, there are reports about life threatening skin eruptions such as DRESS, toxic epidermal necrolysis triggered by TMP-SMX [6] .

We describe 31-year-old female with pancytopenia and generalized livedoid reticularis which have occurred after introduction of trimetophrim-sulfamethoxazole (TMP-SMX). The rash and bone morrow suppression disappeared after withdrawal of the drug.

\section{CASE REPORT}

A 31-year-old woman with acute otitis media presented with widespread eruption for 4 days. She was prescribed TMP-SMX for acute otitis media a week before the occurrence of the eruption. At initial presentation, her main complaint was slightly burning sense of the eruption. She did not give any history of joint symptoms, fever, malaise, thrombotic episodes and abortus. Family history was unremarkable. The rash was not cold induced. The skin examination revealed general reticular livedoid eruption more intense on the proximal part of lower extremities (Fig. la) and upper parts of trunk (Fig. 2a). Oral and genital mucosa, nails and scalp were not involved. Lymph nodes were not enlarged. Other systemic examinations were normal. She was not taking any medication except TMP-SMX for otitis media. TMP-SMX therapy was discontinued.

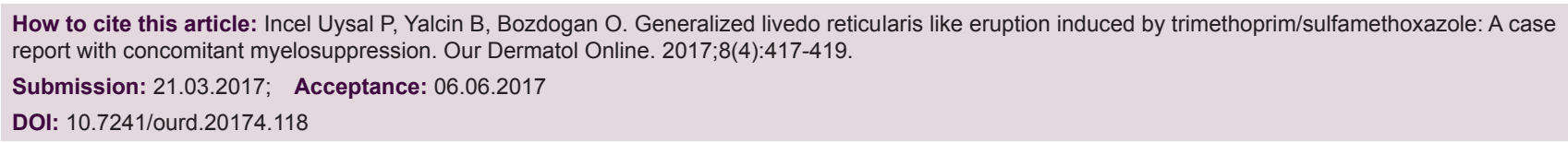


Punch biopsy specimen was obtained from left thigh and an extensive laboratory tests for the causes of livedo reticularis was performed. Leukocytopenia $\left(2.5 \times 10^{3}\right.$ leukocytes $)$, mild thrombocytopenia $\left(133 \times 10^{3}\right.$ thrombocytes), anemia (Hb, $11 \mathrm{~g} / \mathrm{dl}$; Htc, $35.9 \%$ ) were observed in the blood count. Peripheral blood smear revealed hypochromic microcytic red cells without cell atypia. Abnormal biochemical parameters were as follows: ESR, $22 \mathrm{~mm} / \mathrm{h}$; ASO, $235 \mathrm{IU} / \mathrm{ml}, \mathrm{Fe}, 19 \mu \mathrm{g} / \mathrm{dl}$. Urine analysis was normal. Comprehensive metabolic profile, protein $\mathrm{C}$ and $\mathrm{S}$, lupus anticoagulant, antithrombin III, antiphospholipid antibodies, cryoglubulines, antinuclear antibodies, complement levels, rheumatoid factor, coagulation studies were normal. HIV and VDRL serology tests were negative. Local moisturizers and topical steroids were prescribed. Patient was consulted with haematology. Haematological abnormalities were associated with TMP-SMX use. Iron supplement was started with the diagnosis of iron deficiency anemia. Histological examination showed chronic lymphocytic inflammatory cell infiltrate along with a few eosinophiles and marked edema in the dermis (Fig. 3).

The patient was asked to come for follow-up every week. The rash and myelosuppression were persisted for the first week. Her blood parameters (WBC, $4.8 \times 10^{3} / \mu \mathrm{L}$; PLT, $\left.195 \times 10^{3} / \mu \mathrm{L}\right)$ increased 2 weeks after the discontinuation of drug. Slight increase of haemoglobin level $(\mathrm{Hb}, 11.8 \mathrm{~g} / \mathrm{dl})$ was achieved at third week control. Gradual resolution of the eruption was observed over the next month (Figs lb - 2b).

\section{DISCUSSION}

TMP-SMX which is one of the oldest antimicrobial agents inhibits sequential steps in the synthesis of tetrahydrofolic acid. Thrombocytopenia and leucopenia are the most common hematologic side effects due to TMP-SMX. On the other hand wide range of haematological toxicities have been described [7]. These toxities are more common in adults. Thrombocytopenia, leukocytopenia and iron deficiency anemia were present in our case. Her clinic was not critic. Two weeks after discontinuation of the drug, increased levels of the white blood cells and platelets were achieved.

Skin rashes are one of the most common side effects of TMP-SMX. Even though majority of these reactions are mild, diffuse, morbilliform reactions, serious reactions

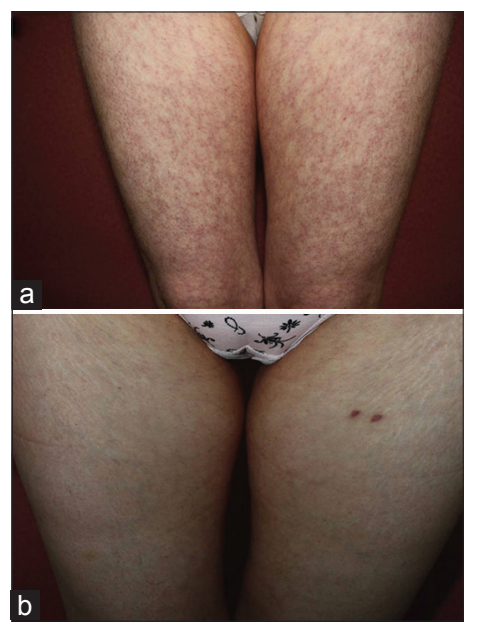

Figure 1: Marked livedo reticularis on the thighs of the patient at initial presentation (a). Improvement of the eruption after discontinuation TMP-SMX (b).

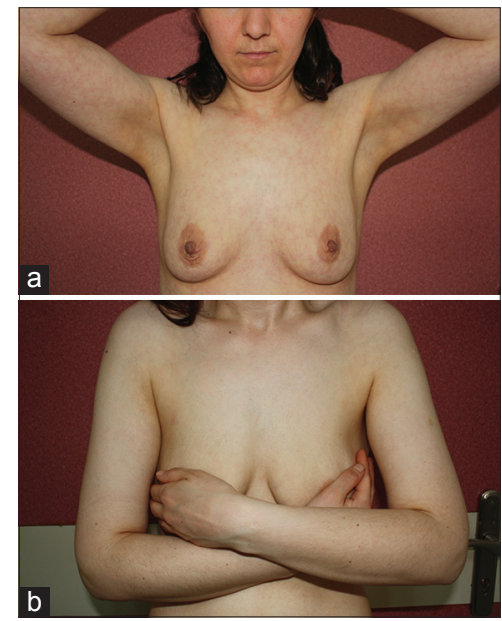

Figure 2: Reticular eruption on the trunk (a). Complete clearance of the lesions at 1 -month follow-up (b).

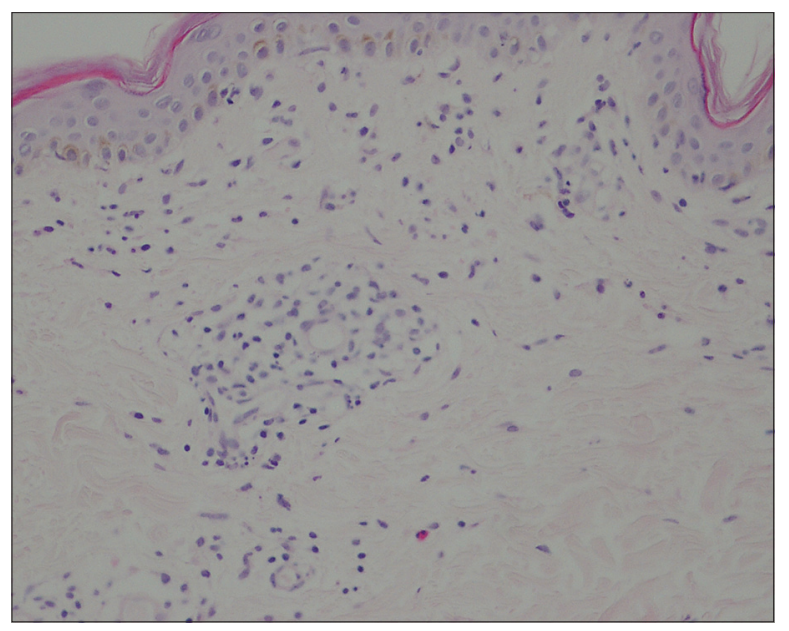

Figure 3: Nonspecific inflammatory infiltration including a few eosinophils and edema in the dermis. Original magnification, x200, H\&E. 
have occurred. Our patient has used TMP-SMX for a week preceding the eruption. The abrupt onset of the condition after TMP-SMX therapy suggested us a causal relationship between the drug and rash. However we performed other laboratory tests with the aim of investigating and excluding potential cause of the livedo reticularis. Similarly some other reports in the literature, histopathology did not yield diagnosis in our patient. Nonspesific histopathological changes without vasculitis were observed in most of the cases of drug induced livedo reticularis like as in our case $[3,5,8]$. Our case presented easily recognizable clinical picture of livedo reticularis. Nevertheless, because of nonspecific microscopical findings without any clue of the condition, a diagnosis of livedo reticularis-like eruption secondary to TMP-SMX was made. Based on uncomplicated clinic and subtle subjective symptoms of our patient we did not consider any systemic therapy. Two weeks after cessation the medication, partial improvement of the discoloration was observed. At fourth week of the initial examination, rash was disappeared completely. However re-challenge was not attempted because of the relapse risk of drug induced bone morrow toxicity. In patients with livedo reticularis or racemosa identifying the underlying cause is important for management. Although it is not fully understood, it is believed that Amantadine -a well known causative agent for livedo reticularis- leads to cathecolamine depletion [8,9]. Recently, it has been reported that there are similar cases induced with some agents such as gefitinibe, imatinibe, dapsone, rasagiline $[3-5,10]$.

\section{CONCLUSION}

This case, to our knowledge, is the first report relating TMP-SMX to livedo reticularis like eruption. Rash with mild hematologic toxicity was another interesting aspect of our case. As it is understood from some reports in literature the exact mechanism leading this widespread eruption with vascular origin is unknown for today. Obviously drug induced reticular eruptions need more understanding. In conclusion, in view of wide use of TMP-SMX, we want to underlie this mild, rare adverse cutaneous reaction.

\section{REFERENCES}

1. Quaresma MV, Gomes AC, Serruya A, Vendramini DL, Braga L, Bucard AM. Amantadine-induced livedo reticularis--Case report. An Bras Dermatol. 2015;90:745-7.

2. Hayes BB, Cook-Norris RH, Miller JL, Rodriguez A, Zic JA. Amantadine-induced livedo reticularis: a report of two cases. J Drugs Dermatol. 2006;5:288-9.

3. Martinez-Gonzalez MC, del Pozo J, Yebra-Pimentel MT, Perez M, Almagro M, Fonseca E. Livedoid skin reaction probably due to imatinib therapy. Ann Pharmacother. 2007;41:148-52.

4. Strowd LC, Lee AD, Yosipovitch G. Livedo reticularis associated with rasagiline (azilect). J Drugs Dermatol. 2012;11:764-5.

5. Semira, Wafai ZA, Zulfkar Q, Sameem F. Livedo reticularis associated with dapsone therapy in a patient with chronic urticaria. Indian J Pharmacol. 2014;46:438-40.

6. Joint Task Force on Practice P, American Academy of Allergy A, Immunology, American College of Allergy A, Immunology, Joint Council of Allergy A, et al. Drug allergy: an updated practice parameter. Annals of allergy, asthma \& immunology: official publication of the American College of Allergy, Asthma, \& Immunology. 2010;105:259-73.

7. Gleckman R, Altschuller C. Trimetophrim-Sulfamethoxazole. In: Gorbach SL BJ, Blacklow NR., editor. Infectious diseases. PA, USA: Lippincott Williams and Wilkins; 2004. p. 247.

8. Shealy CN, Weeth JB, Mercier D. Livedo reticularis in patients with parkinsonism receiving amantadine. Jama. 1970;212:1522-3.

9. Sladden MJ, Nicolaou N, Johnston GA, Hutchinson PE. Livedo reticularis induced by amantadine. Br J Dermatol. 2003;149:656-8.

10. Blume JE, Miller CC. Livedo reticularis with retiform purpura associated with gefitinib (Iressa). Int J Dermatol. 2007;46:1307-8.

Copyright by Pinar Incel Uysal, et al. This is an open-access article distributed under the terms of the Creative Commons Attribution License, which permits unrestricted use, distribution, and reproduction in any medium, provided the original author and source are credited.

Source of Support: Nil, Conflict of Interest: None declared. 